\title{
Análise de interfaces de sistemas restauradores diretos em esmalte e em dentina humanos
}

\author{
Interface analysis of direct restorative \\ systems on human enamel and dentin
}

\author{
Eric Costa Carvalho' ${ }^{1}$ Jayme Pereira de Gouvêa ${ }^{1}$, \\ Ágatha Borges Teixeira ${ }^{1}$; Tereza Cristina Favieri de Melo-Silva ${ }^{2}$, \\ Cláudio Luís de Melo-Silva ${ }^{2}$
}

\footnotetext{
${ }^{1}$ Universidade Federal Fluminense, R. 12 - Vila Santa Cecília, Volta Redonda, Rio de Janeiro, Brasil.

${ }^{2}$ UniFOA, Avenida Paulo Erlei Alves Abrantes, 1325 - Três Poços, Volta Redonda, Rio de Janeiro, Brasil. e-mail: costa_eric1@hotmail.com,jpg@metal.eeimvr.uff.br, htaborges@gmail.com, terezafmelo@ig.com.br, claudiolmelo@ig.com.br
}

\section{RESUMO}

O presente estudo visou caracterizar a interface entre resina e substrato dentário submetida aos processos restauradores convencional e autocondicionante, levando a observar a presença de gaps e infiltração dos sistemas adesivos nos substratos dentários. A análise foi realizada em dois substratos dentários: o esmalte e a dentina. Seis dentes hígidos, previamente coletados e armazenados, foram seccionados em três planos de corte distintos para avaliar a adesão em relação à morfologia dentária. Para isto, foi utilizado um sistema adesivo universal aplicado de maneira convencional e autocondicionante. A técnica autocondicionante não é eficiente em esmalte, apresentando formação de gaps. Já a convencional é mais eficiente devido ao processo de desmineralização por um ácido forte, ocasionando a penetração do adesivo. Para a dentina, a técnica convencional formou uma camada híbrida espessa, irregular e com penetração de tags resinosos e a autocondicionante formou uma camada híbrida mais fina, homogênea e sem tags. O tamanho da camada híbrida e penetração dos tags não influenciam na resistência adesiva, sendo este fator dependente da qualidade da camada híbrida e sua interação com o substrato.

Palavras-chave: compósito resinoso, sistemas adesivos, esmalte, dentina, camada híbrida.

\section{ABSTRACT}

The present study aimed to characterize the interface between resin and dental substrate submitted to the etch-and-rinse and self-etching restorative process, leading to the presence of gaps and infiltration of adhesive systems in dental substrates. The analysis was done in two dental substrates: enamel and dentin. Six healthy teeth, previously collected and stored were sectioned into three distinct axes to evaluate adherence in relation to dental morphology. A universal adhesive system was applied in etch-and-rinse and self-etch way. The self-etch technique is not effective in enamel, so gaps were produced. But etch-and-rinse is more efficient due to the demineralization process by a strong acid, generating adhesive mechanical imbrications. For dentin, etch-and-rinse formed a thick hybrid layer, irregular and penetration of resin tags; and self-etch formed a thinner hybrid layer, homogeneous and without tags. The size of the hybrid layer and penetration of tags didn't influence the bond strength, which is dependent on the factor of quality hybrid layer and its interaction with the substrate.

Keywords: composite resin, adhesive systems, enamel, dentin, hybrid layer.

\section{INTRODUÇÃO}

Os materiais restauradores dentários podem ser metálicos, cerâmicos, poliméricos e compósitos (metalocerâmicos, por exemplo). O material restaurador deve ser biocompatível, inerte biologicamente, quimicamente durável e possuir propriedades mecânicas compatíveis com o material biológico. Além do mais, no caso das restaurações em dentes anteriores, o fator estética é relevante, ou seja, o material deve ter cor estável [1]. 
Tratando especificamente dos polímeros envolvidos em restaurações dentárias diretas, pôde-se observar ao longo da última década que os compósitos resinosos e os sistemas adesivos foram os materiais odontológicos que mais passaram por melhorias. Apesar do considerável progresso de adesão destes compósitos aos substratos dentários, procuram-se materiais restauradores que, além de serem biologicamente compatíveis com a estrutura dentária, possuam força suficiente para suportar os esforços mastigatórios [2].

A aplicação de compósitos resinosos em restaurações diretas é usual em odontologia por garantir um fator de conservação ao preparo cavitário, proporcionando uma menor remoção de estrutura dental. Desde sua concepção, as técnicas de adesão e as formulações de sistemas adesivos vêm sendo modificados. O processo de adesão é essencialmente micromecânico para o esmalte enquanto que em dentina é por meio da formação de uma camada híbrida. Nos últimos anos, as empresas têm buscado desenvolver materiais com técnicas simplificadas objetivando um protocolo clínico de adesão mais ágil e menos suscetível a problemas ocasionados por sua sensibilidade técnica [3].

Durante muitos anos, uma das principais deficiências em odontologia restauradora foi a adesão do material resinoso ao substrato dentário. Foram exploradas tentativas de se obter ligação entre resinas e estrutura dentária com a modificação da superfície do dente por meio de tratamento químico para produzir uma nova superfície sobre a qual materiais presentes podem se aderir. Esta abordagem introduz a utilização do ácido fosfórico, que na indústria age em preparações para tratar as superfícies metálicas e obter melhor aderência dos revestimentos de tintas e resinas. Analogamente, a utilização de condicionamento ácido em odontologia se fez presente ao perceber que o tratamento ácido em substrato dentário poderia tornar a superfície mais receptiva à aderência devido ao processo de desmineralização [4].

Com surgimento do condicionamento ácido do esmalte dentário criou-se uma nova perspectiva para os materiais restauradores adesivos, com a eliminação das macrorretenções adicionais e a minimização do excessivo desgaste da estrutura remanescente. Na dentina, com o condicionamento ácido e o aperfeiçoamento dos adesivos dentinários hidrofílicos, as microrretenções passaram a ser preenchidas, facilitando a superfície de contato entre o substrato úmido e o agente de união [5], contudo, a junção adesiva ainda mostra problemas como degradação hidrolítica, contração de polimerização e permeabilidade [6].

A biodegradação da interface adesivo/resina gera um espaço ( gap) entre o substrato dentário e o compósito, ocasionando assim, diminuição das forças adesivas, falhas da restauração e microinfiltrações [7]. Estas microinfiltrações permitem a passagem de agentes patogênicos como as bactérias cariogênicas que geram as lesões de cárie secundárias. Embora os adesivos atuais proporcionarem forças adesivas imediatas bastante elevadas, a junção adesiva tende a enfraquecer ao longo do tempo, e portanto, tal tecnologia continua em constante desenvolvimento [8].

Com o intuito de melhorar as forças adesivas em longo prazo, surgiram os monômeros funcionais integrados aos sistemas adesivos como, por exemplo, o 4-metacriloxietil trimelítico (4-MET), 2metacriloxietil fenil fosfato hidrogênio (Fenil-P) e o 10-metacriloiloxidecil di-hidrogênio fosfato (10-MDP). Esses monômeros são definidos como sendo um dos seus componentes adesivos mais importantes, pois melhoram a adesão aos tecidos mineralizados através de ligações químicas. Os grupos carboxílicos/fosfato destes monômeros ligam-se ionicamente ao cálcio presente na hidroxiapatita desenvolvendo uma ligação estável e duradoura. O 10-MDP é um dos mais estudados e o que apresenta a melhor performance, principalmente em relação à dentina que é um substrato caracterizado pela difícil adesão ao material restaurador [9].

O presente estudo visou avaliar o tamanho da camada híbrida formada por um sistema adesivo universal aplicado de maneira convencional e autocondicionante, presença de gaps e infiltração desse sistema nos substratos dentários.

\section{MATERIAIS E MÉTODOS}

Para este estudo foram utilizados seis dentes molares humanos hígidos, mantidos em solução de água destilada à temperatura ambiente até o momento de sua utilização. Posteriormente foram submetidos ao protocolo restaurador e então levados ao microscópio eletrônico de varredura (MEV) para observação da interface adesiva, camada híbrida, gaps e tags. Na execução do protocolo restaurador foram utilizados o sistema adesivo Single Bond Universal $\AA^{\circledR}$ e a resina composta Filtek Z350 XT $₫$ ambos do fornecedor 3M ESPE.

\subsection{Preparo da Amostra}

A análise aconteceu apenas na parte coronária do dente, sendo assim, as raízes foram cortadas e o dente lavado e seco. Em seguida, os dentes passaram por três cortes distintos: axial, coronal e sagital. Os dentes foram seccionados com discos diamantados em baixa rotação (de 250 a $300 \mathrm{rpm}$ ) pela máquina de corte ISOMET 1000. A Figura 1 evidencia os três planos de corte que foram executados na estrutura dentária. 
Posteriormente, a parte seccionada foi aplainada com lixas d'água de granulação 600, 800 e 1200 na lixadeira Aropol S (AROTEC), e então, polida com solução de alumina de 1 e $0,05 \mu \mathrm{m}$ de modo que não existam ranhuras ao observar o material por microscopia. Para a retirada dos excessos de debris (resíduos) os espécimes foram limpos com algodão e água corrente, pois devido à fragilidade do material a utilização da cuba ultrassônica poderia ocasionar fraturas no material dentário [10].

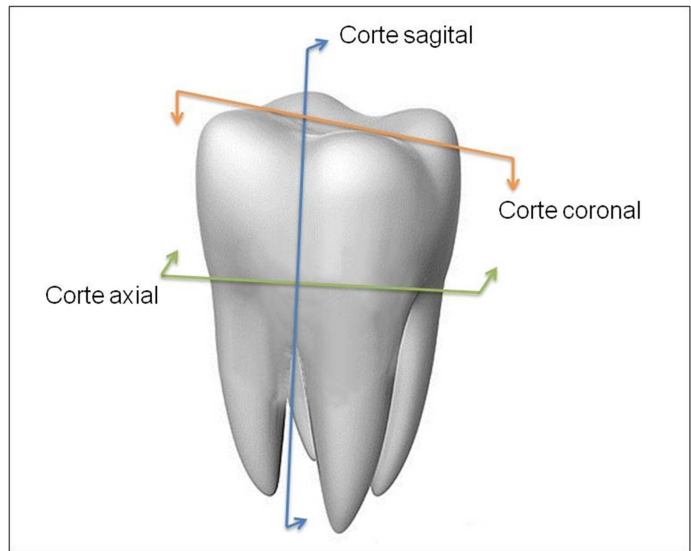

Figura 1: Desenho esquemático dos três planos de corte efetuados no projeto. Adaptado Dreamstime [11].

\subsection{Tratamentos Adesivos e Restauradores}

Cada dente foi seccionado em um tipo de corte diferente e as duas técnicas foram aplicadas a cada corte. Nos dentes submetidos ao tratamento convencional, os espécimes foram condicionados com ácido fosfórico a $37 \%$ p/p por $30 \mathrm{~s}$ em esmalte e $15 \mathrm{~s}$ em dentina, seguido de lavagem por $20 \mathrm{~s}$ e secagem apenas para o esmalte, já a dentina foi protegida com uma bola de algodão para evitar o ressecamento das fibras colágenas. Posteriormente, o adesivo Single Bond Universal (3M ESPE) foi aplicado em duas camadas sobre o substrato dentário de forma ativa (esfregando) por 15 segundos, depois seco com jato de ar a $20 \mathrm{~cm}$ durante 5 segundos e com fotoativação por 10 segundos, seguindo orientação do fabricante. O sistema adesivo foi aplicado de forma ativa visto que o solvente é à base de etanol.

Os espécimes submetidos ao tratamento autocondicionante não foram condicionados com ácido, sendo assim, o adesivo Single Bond Universal agiu de forma autocondicionante, contando apenas com o poder acidificante do primer do material (éster fosfato de metacrilato). O adesivo também foi levemente aplicado em duas camadas de forma ativa sobre o esmalte e dentina por 15 segundos, seguido de secagem com jato de ar a $20 \mathrm{~cm}$ durante 5 segundos e fotoativação por 10 segundos.

Depois de realizado o protocolo adesivo, os dentes foram restaurados com resina Filtek Z350 XT (3M ESPE), cortados de modo a observar a interface resina/substrato dentário, e por fim, lixados e polidos conforme previamente elucidado. A Figura 2 ilustra o esquema de preparo da amostra para posterior análise microscópica.

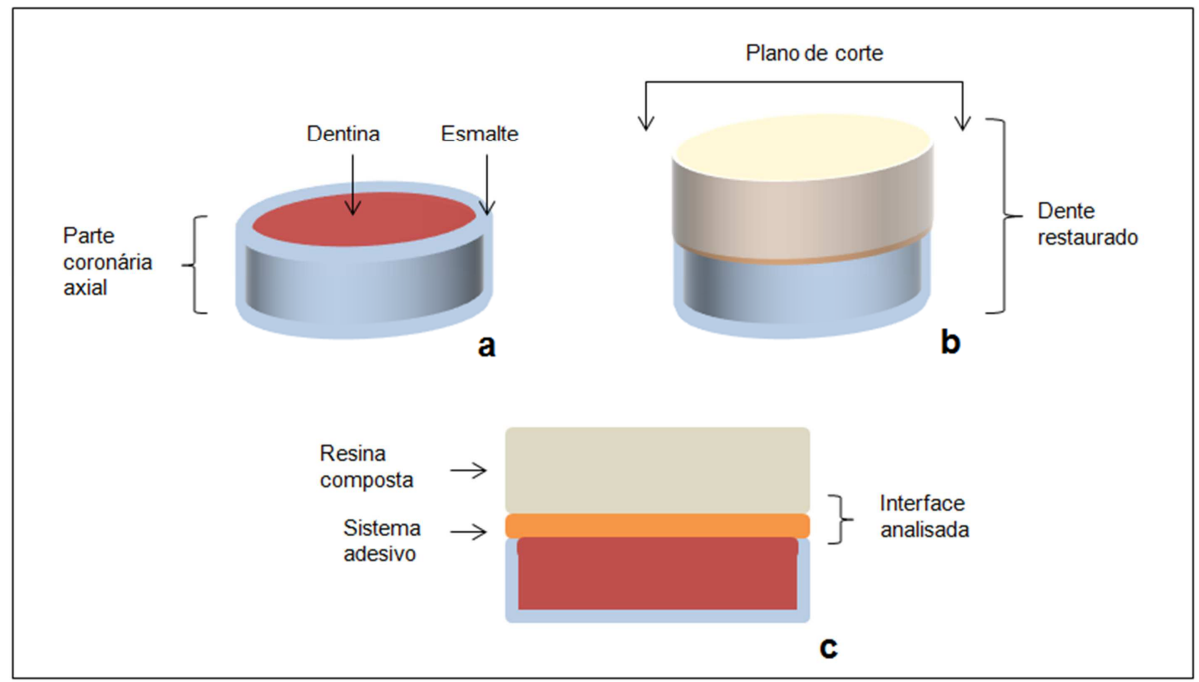


Figura 2: Desenho esquemático do procedimento de preparo da amostra para realização de análise de interfaces: a) dente seccionado no plano axial; b) dente restaurado com sistema adesivo e resina composta; c) amostra seccionada e preparada para análise de interface em microscopia eletrônica de varredura.

\subsection{Análise de Microscopia}

Após corte e polimento, as amostras foram condicionadas com ácido fosfórico a $50 \% \mathrm{v} / \mathrm{v}$ por $5 \mathrm{~s}$ para remoção da smear layer (lama oriunda do preparo cavitário), e posteriormente, foram desidratadas por imersão em etanol, com concentrações crescentes: 70, 80, 90 e 100\% por 15 minutos em cada solução, sendo que no álcool absoluto (100\%), estas permaneceram por 30 minutos. Após secarem, as superfícies das amostras foram fixadas sobre stubs metálicos, com auxílio de fita de carbono e então encobertas com ouro (camada de $1 \mathrm{~nm}$ ) pelo processo de metalização, aparelho EMITECH K550X. Por fim, os espécimes foram analisados em microscópio eletrônico de varredura (EVO MA 10 ZEISS) no modo elétrons secundários para análise de interface.

\section{RESULTADOS E DISCUSSÃO}

Os dentes foram seccionados em três planos de cortes distintos, que depois de restaurados, tiveram sua morfologia de interface caracterizada. Dependendo da técnica restauradora aplicada a determinado substrato dentário pode-se levar a diferentes níveis de desmineralização e penetração do adesivo, e consequentemente, ocasionar diferentes qualidades de selamento da interface e posterior longevidade dos tratamentos. Os resultados desse estudo foram resumidos de modo a identificar melhor os pontos principais que serão expostos nos próximos itens conforme Tabela 1.

Tabela 1: Compilação dos dados qualitativos extraídos da análise de interface por microscopia eletrônica de varredura.

\begin{tabular}{|c|c|c|c|c|c|}
\hline Substrato & Técnica & Ácido & Gaps & Tags & Adesão \\
\hline \multirow{2}{*}{ Esmalte } & Convencional & Forte & Não & Sim & \multirow{4}{*}{$\mathrm{Mec} / \mathrm{Qu}$} \\
\hline & Autocondicionante & Fraco & Sim & Não & \\
\hline \multirow{2}{*}{ Dentina } & Convencional & Forte & Não & Sim & \\
\hline & Autocondicionante & Fraco & Não & Não & \\
\hline
\end{tabular}

\subsection{Esmalte}

O condicionamento ácido do esmalte provoca uma irregularidade superficial, formando microporosidades e aumentando sua energia de superfície. Quando um adesivo ou resina fluida é aplicado sobre a superfície, penetra no interior do substrato através destas microporosidades por ação capilar. Depois da polimerização, prolongamentos resinosos são formados, os tags, que penetram os prismas do esmalte e fornecem retenção micromecânica. [12,13].

Devido às características ortotrópicas do esmalte, o posicionamento dos prismas do esmalte influenciou na resistência de união. Este posicionamento proporcionou uma maior penetração ou infiltração do adesivo também denominado de embricamento mecânico, ocasionando assim, aumento de sua resistência adesiva. As Figuras 3 e 4 ilustram as interfaces esmalte/resina. 


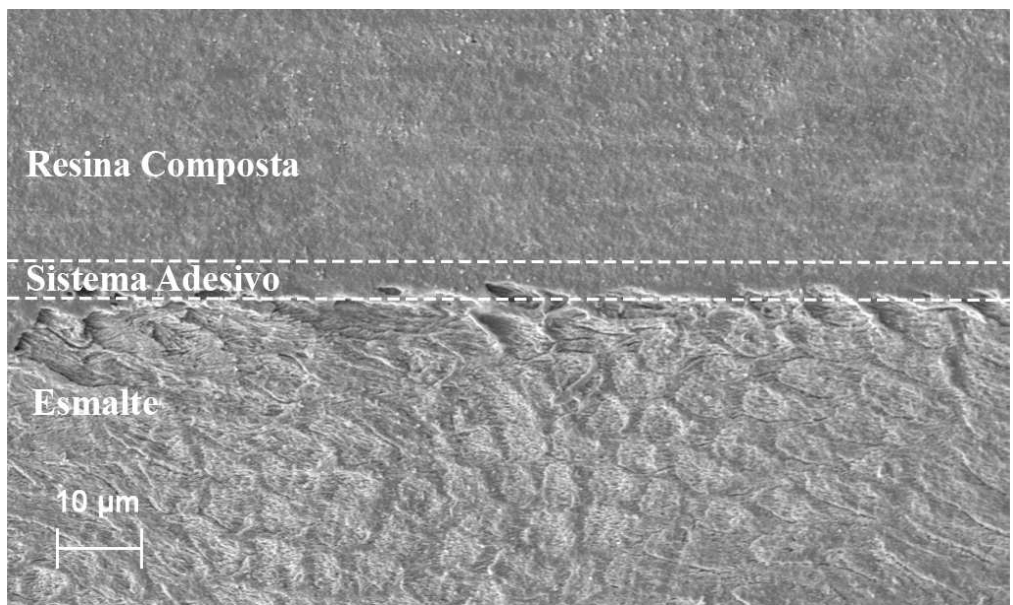

Figura 3: Imagem micrográfica da interface esmalte/resina, corte axial e técnica convencional. Imagem MEV.

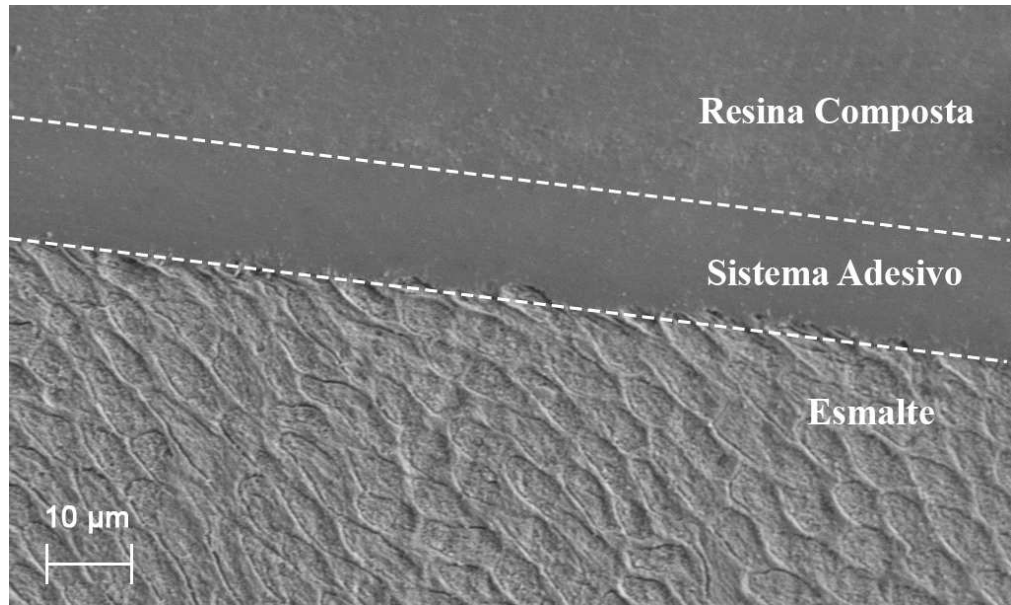

Figura 4: Imagem micrográfica da interface esmalte/resina, corte sagital e técnica convencional. Imagem MEV.

Observa-se na Figura 3 uma morfologia arredondada dos prismas do esmalte, possibilitando uma maior desmineralização e gerando maior penetração de topo do sistema adesivo. Isso se denota na pequena camada de sistema adesivo remanescente do processo de adesão (em torno de $1 \mu \mathrm{m}$ ), uma vez que houve uma grande infiltração do adesivo. O mesmo não foi evidenciado na Figura 4, pois os prismas se encontram mais alongados pela superfície do esmalte gerando barreiras para penetração do sistema adesivo, e assim, formando uma camada adesiva maior que no corte axial (em torno de $10 \mu \mathrm{m}$ ).

A Figura 5 retrata a técnica de adesão autocondicionante. Esta técnica é ineficiente em esmalte, pois o agente acidificante presente no frasco do adesivo não é forte o suficiente para desmineralizar o substrato, gerando gaps na interface que enfraquecem a restauração, e posteriormente, causarão danos à estrutura. Os sistemas adesivos universais permitem a aplicação da técnica de condicionamento ácido parcial em esmalte, proporcionando as vantagens de um sistema adesivo convencional. Esta técnica consiste no condicionamento ácido das margens do esmalte, permitindo a ligação química dos cristais de apatita carbonatados remanescentes no substrato [14]. 


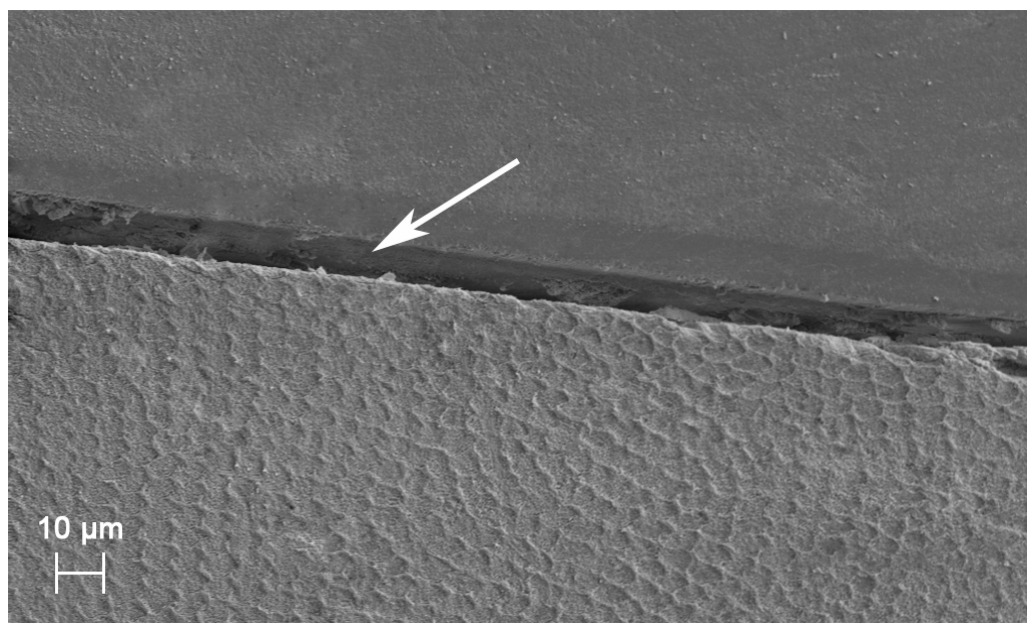

Figura 5: Imagem micrográfica da interface esmalte/resina, corte axial e técnica autocondicionante, onde a seta indica a faixa de gap presente na estrutura. Imagem MEV.

Em relação ao esmalte, a técnica autocondicionantes não produz tantas retenções quanto no condicionamento ácido, acarretando numa baixa resistência adesiva, falhas clínicas e descoloração nas margens do esmalte após restauração [15]. Em um prévio estudo submetendo o esmalte a ensaios mecânicos de microcisalhamento com o objetivo de se observar a resistência adesiva da interface resina/esmalte, a técnica de adesão autocondicionante apontou baixos valores de resistência, em torno de $8 \pm 3 \mathrm{MPa}$, não havendo distinção estatística entre os cortes. Diferentemente dos valores apontados para a técnica convencional, sendo $30 \pm 3 \mathrm{MPa}$ para o corte axial e $24 \pm 1 \mathrm{MPa}$ para coronal e sagital [16].

\subsection{Dentina}

Desde o princípio dos estudos com relação a sistemas adesivos, a dentina tem se mostrado mais complexa que o esmalte. Os adesivos interagem majoritariamente de maneira mecânica, mas também podendo ocorrer de forma química, mesmo que de maneira menos intensa. $\mathrm{O}$ mecanismo micromecânico influi na retenção do compósito resinoso através da infiltração nas microporosidades criadas [8].

De maneira semelhante ao esmalte, o sistema adesivo universal foi aplicado de modo convencional e autocondicionante nos três planos de corte. Nas técnicas convencionais observou-se a formação de uma fina camada híbrida irregular (oriunda da interação do sistema adesivo com as fibras colágenas da dentina) e presença de tags resinosos (sendo a penetração do sistema adesivo nos túbulos dentinários), conforme evidenciado na Figura 6.

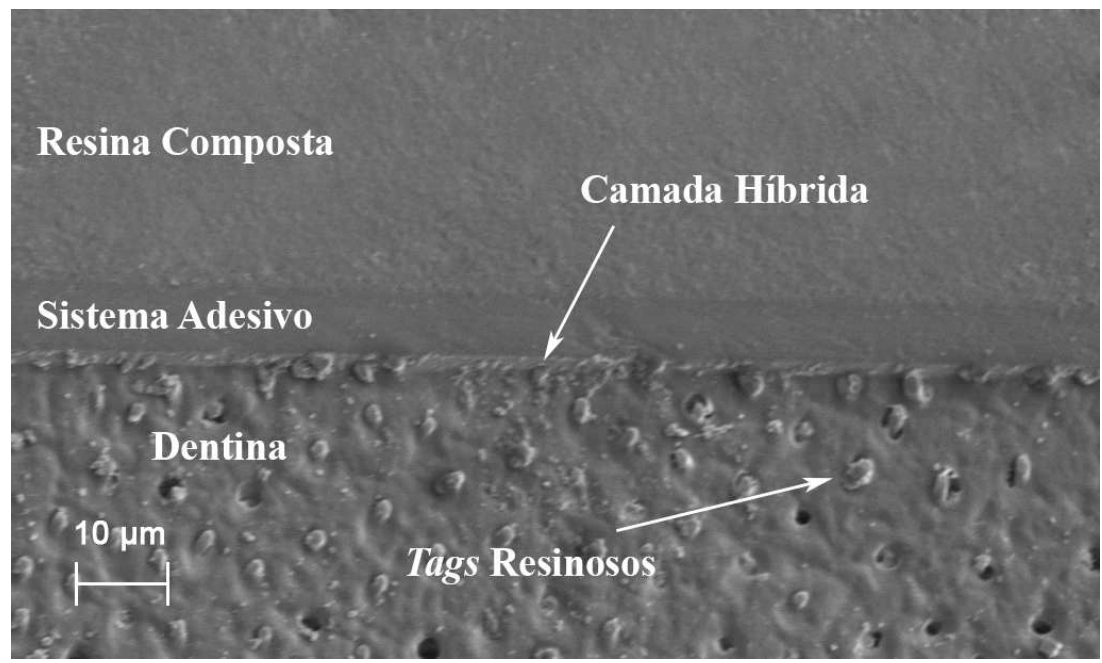

Figura 6: Imagem micrográfica da interface dentina/resina, corte coronal e técnica convencional. Imagem MEV. 
Os tags resinosos (penetração dos sistemas adesivos nos túbulos dentinário) são mais facilmente observados em dentina, uma vez que o adesivo penetra o túbulo dentinário e depois do processo de secção da amostra expõe os tags. A camada híbrida varia de 1 a $2 \mu \mathrm{m}$ e também varia do plano de corte em estudo, sendo mais facilmente observada nos cortes axiais que ocorre uma penetração de topo nos túbulos dentinários e no processo de secção é exposta lateralmente, bem como os tags alongados conforme demonstrado na Figura 7.

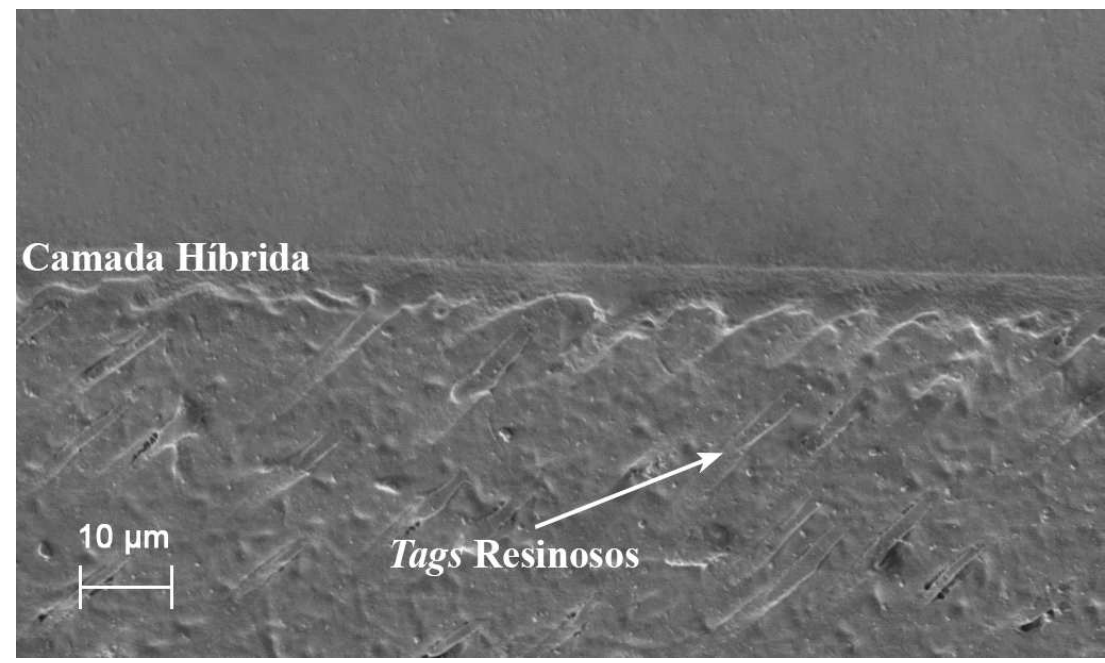

Figura 7: Imagem micrográfica da interface dentina/resina, corte axial e técnica convencional. Imagem MEV.

A utilização da técnica convencional, devido ao seu condicionamento ácido, desmineraliza a dentina causando a exposição dos túbulos e aumentando a permeabilidade da dentina. Também ocorre a remoção dos smear plugs (lama interna oriunda do preparo cavitário ou smear layer interna) que obstruem os túbulos dentinários $[17,18]$.

Pôde-se verificar que a técnica convencional originou uma camada híbrida mais espessa, irregular e com prolongamentos resinosos evidentes em se tratando de sistemas adesivos convencionais [19]. A diferença se dá na ausência de uma zona hibridóide quando se trata de sistemas adesivos universais. Esta zona é característica de uma inadequada infiltração de monômeros resinosos na parte inferior da camada híbrida, evitando o selamento da mesma. Com a aplicação dos sistemas universais, nanocamadas de sal são formadas auxiliando neste processo de selamento.

Nas técnicas autocondicionantes observou-se a formação de uma camada híbrida mais homogênea e ausência de tags resinosos (ou rasos), conforme demonstrado na Figura 8.

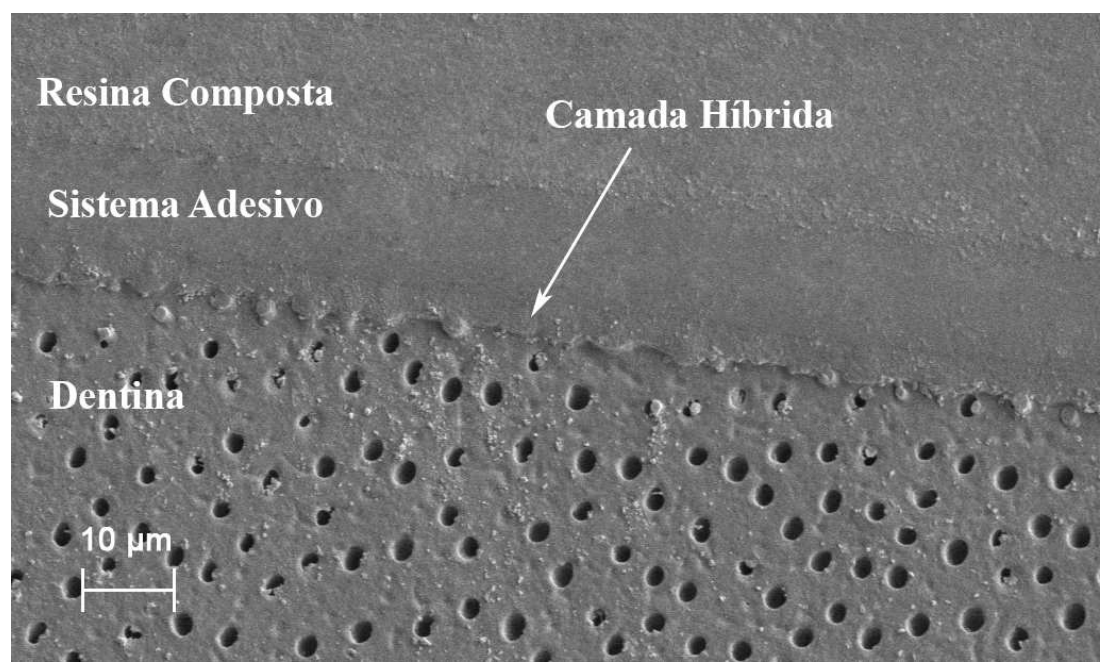

Figura 8: Imagem micrográfica da interface dentina/resina, corte sagital e técnica autocondicionante. Imagem MEV.

A classificação do $\mathrm{pH}$ dos sistemas adesivos autocondicionantes influencia na profundidade da desmineralização da dentina. Quanto menor o pH, maior a capacidade de penetração profunda. Os adesivos autocondicionantes fracos possuem um $\mathrm{pH}$ em torno de 2 que desmineraliza apenas superficialmente ou 
parcialmente a dentina, deixando cristais de hidroxiapatita ao redor do colágeno, auxiliando na proteção contra degradação. Os adesivos autocondicionantes fortes têm um pH de 1 ou inferior. Essa alta acidez resulta em elevados efeitos de desmineralização se assemelhando ao da técnica convencional. [14]. No caso da técnica autocondicionante, a smear layer participa no processo de adesão, auxiliando na formação da camada híbrida. Nos autocondicionantes médio e suaves os smear plugs são ligeiramente desmineralizados, contribuindo para infiltração da resina [20,21].

Outro ponto é que em técnicas convencionais é necessário lavagem e secagem do substrato dentário para garantir um grau de umidade da dentina com o intuito de se evitar que as fibras colágenas colabem, ou seja, que sua estrutura tubular comprima fazendo com que suas paredes se toquem. Já para os autocondicionantes, não existe essa necessidade uma vez que não ocorre um prévio condicionamento ácido. Também em cavidades profundas com diâmetros de túbulos maiores o uso de técnicas convencionais pode acarretar em sensibilidade pós-operatória, diferentemente do ocorrido com os autocondicionantes [14].

Os gaps nas restaurações em dentina acontecem mais comumente devido à composição e micromorfologia da mesma [22]. Se o gap ocorre entre o topo da camada híbrida e a camada de adesivo, a dentina permanecerá selada, porém se ele ocorrer entre camada híbrida e dentina, a dentina não estará selada e poderá ocorrer invasão bacteriana, risco de desmineralização, sensibilidade dentária e comprometimento pulpar [23]. O único grupo analisado neste projeto e que foi observado formação de gaps é o esmalte/autocondicionante. Ou seja, nenhum gap foi encontrado na restauração da dentina. Isso se deve, mais uma vez, à utilização do sistema adesivo universal, em que o 10-MDP agirá como agente selante.

Assim como para o esmalte, também foram realizadas prévias análises de resistência adesiva por meio de ensaios mecânicos de microcisalhamento para a dentina. Os espécimes submetidos à técnica autocondicionante obtiveram uma resistência adesiva homogênea para os três cortes $(18 \pm 4 \mathrm{MPa})$ e estatisticamente semelhante à convencional. Logo, a resistência adesiva da dentina está mais fortemente ligada à formação da camada híbrida do que ao poder de desmineralização do ácido, diferentemente do que ocorre no esmalte [16].

Este estudo não contempla, porém, a degradação da camada híbrida ao longo do tempo. Problemas como hidrólise dos polímeros pela absorção de água e degradação do colágeno são observados e podem gerar falhas no dente restaurado [24]. Mas, para uma análise imediata, a utilização de sistemas universais pode garantir uma vedação mais eficaz se comparados com sistemas adesivos de gerações anteriores, e consequentemente, ocasionará maior longevidade nos tratamentos clínicos.

\section{CONCLUSÃO}

Com este trabalho, pode-se concluir que:

A morfologia do esmalte interferiu diretamente no processo adesivo pela utilização da técnica convencional. Ou seja, o posicionamento dos prismas, facilita ou dificulta a penetração do sistema adesivo. No caso do plano axial houve uma desmineralização de topo ou do núcleo do prisma, já nos outros cortes houve uma desmineralização da periferia prismática, ocasionando uma menor penetração do sistema adesivo. Para a técnica autocondicionante a morfologia não interferiu, pois o poder acidificante do sistema adesivo não foi suficientemente forte para gerar uma efetiva desmineralização do esmalte e consecutiva penetração do adesivo.

A morfologia da dentina, ou seja, o direcionamento dos túbulos não interferiu no processo adesivo, pois neste caso, essa resistência está diretamente ligada à qualidade da camada híbrida, conforme previamente abordado. Sendo assim, não se faz necessária uma análise em três cortes distintos, diferentemente da abordagem para o esmalte.

A camada híbrida formada sob a técnica convencional foi em torno de $2 \mu \mathrm{m}$ e autocondicionante em torno de $1 \mu \mathrm{m}$. Os gaps estiveram presentes apenas nos grupos esmalte/autocondicionante uma vez que o poder desmineralizador do sistema adesivo não foi forte o suficiente para gerar microporosidades para penetração do adesivo, e consequentemente, criar retenções. A presença de tags resinosos foi observada em dentina/convencional, pois a prévia aplicação do ácido removeu a smear layer e permitiu a penetração do adesivo nos túbulos dentinários. Porém, conforme abordado, os tags não estão associados à resistência adesiva.

\section{AGRADECIMENTOS}

O presente trabalho foi realizado com apoio da Coordenação de Aperfeiçoamento de Pessoal de Nível Superior - Brasil (CAPES) - Código de Financiamento 001. 


\section{BIBLIOGRAFIA}

[1] SAKAGUCHI, R. L., POWERS, J. M. Craig, materiais dentários restauradores, 13 ed., Rio de Janeiro, Elsevier, 2012.

[2] ORÉFICE, R. L., DISCACCIATI, J. A. C., NEVES, A. D., et al. "In situ evaluation of the polymerization kinetics and corresponding evolution of the mechanical properties of dental composites". Polymer Testing, v. 22, pp. 77-81, 2003.

[3] KUBO, C. S., Resistência de união ao microcisalhamento de sistemas adesivos distintos em substrato dentinário normal e hipermineralizado artificialmente. Dissertação de M.Sc., Universidade Estadual Paulista, São Paulo. 2013.

[4] BUONOCORE, M.G. "A simple method of increasing the adhesion of acrylic filling materials to enamel surfaces”. Journal of Dental Research, v. 34, n.6, pp. 849-853, 1955.

[5] PERDIGÃO, J., RITTER, A.V. “Adesão dos tecidos dentários”. In: BARATIERI, L.N. et al. pp. 85-128. Odontologia restauradora: fundamentos e possbilidades. São Paulo, Ed. Santos, 2001.

[6] BISPO, L. B. “Adesivos dentinários: interações com a smear layer”. Revista Dentística, v. 9, n. 19, pp. 14, 2010.

[7] LIU, Y., TJÄDERHANE, L., BRESCHI, L. et al. "Limitations in bonding to dentin and experimental strategies to prevent bond degradation”. Journal of Dental Research, v. 90, n. 8, pp. 953-968, 2011.

[8] PERDIGÃO, J., REIS, A., LOGUERCIO, A. D. "Dentin adhesion and MMPs: A Comprehensive Review”. Journal of Esthetic and Restorative Dentistry, v. 25, n. 4, pp. 219-241, 2013.

[9] YOSHIDA, Y., YOSHIHARA, K., HAYAKAWA, S. et al. "HEMA Inhibits Interfacial Nanolayering of the Functional Monomer MDP”. Journal of Dental Research, v. 91, n. 11, pp. 1060-1065, 2012.

[10] CUY, J. L., MANN, A. B., LIVI, K. J., et al. "Nanoindentation mapping of the mechanical properties of human molar tooth enamel”. Archives of Oral Biology, v. 47, pp. 281-291, 2002.

[11] DREAMSTIME, https://pt.dreamstime.com/collections_item.php?collectionid=12185\&sortcriteria=6, Acessado em janeiro de 2019.

[12] CARDOSO M., NEVES A. A, MINE, A. et al., "Current aspects on bonding effectiveness and stability in adhesive dentistry". Australian Dental Journal, v. 56, n. 1, p. 31-44, 2011.

[13] PERDIGÃO, J., SEZINANDO, A. Enamel and dentin bonding for adhesive restorations. In: Nonmetallic biomaterials for tooth repair and replacement, $1^{\mathrm{a}}$ edição, Woodhead Publishing, pp. 45-89, 2012.

[14] MARCHESI, G., FRASSETTO, A., MAZZONI, A. et al. "Adhesive performance of a multi-mode adhesive system: 1-Year in vitro study", Journal of Dentistry, v. 42, n.5, pp. 603-612, 2014.

[15] MUÑOZ, M., LUQUE-MARTINEZ, I., MALAQUIAS, P. et al. "In vitro longevity of bonding properties of universal adhesives to dentin”. Operative Dentistry, v. 40, n. 3, pp. 282-292, 2015.

[16] CARVALHO, E.C., MELO-SILVA, T.C.F., MELO-SILVA, C.L. et al. “Avaliação da resistência de união ao microcisalhamento em sistemas restauradores diretos em esmalte e em dentina". In: Congresso Brasileiro de Cerâmica, v. 60, pp. 1524-1535, Águas de Lindoia, Mai. 2016.

[17] COELHO, A., CANTA, J. P., MARTINS, J. N. et al. "Perspetiva histórica e conceitos atuais dos sistemas adesivos amelodentinários - revisão da literatura". Revista Portuguesa de Estomatologia, Medicina Dentária e Cirurgia Maxilofacial, v. 53, n. 1, pp. 39-46, 2012.

[18] BRESCHI, L., FERRACANE, J., CADENARO, M., et al. “Adhesion to Enamel and Dentin”, In: T. HILTON, J. FERRACANE, \& J. BROOME. Summitt's Fundamentals of Operative Dentistry: A Contemporary Approach. Carol Stream, Illinois, EUA: Quintessence Publishing Company, pp. 207- 238, 2013.

[19] MELO-SILVA, T. C. F. Micromorfologia da interface de união sistema restaurador-dentina decídua, em função do sistema adesivo e do instrumento cortante rotatório. Dissertação de M.Sc., Universidade Estadual Paulista, São Paulo. 2005.

[20] VAN MEERBEEK, B., DE MUNCK, J., YOSHIDA, Y., et al. “Adhesion to enamel and dentin: current status and future challenges”, Operative Dentistry, v. 28, n. 3, pp. 215-235, 2003. 
[21] SILVA E SOUZA JUNIOR, M. H.; CARNEIRO, K. G.; LOBATO, M. F. et al. "Adhesive systems: important aspects related to their composition and clinical use". Journal of Applied Oral Science, v. 18, n. 3, pp. 207-214, 2010.

[22] OLMEZ, A., OZTAS, N., BASAK, F. et al. "Comparison of the resin-dentin interface in primary and permanent teeth”, Journal of Clinical Pediatric Dentistry, v. 22, n. 4, pp. 293-298, 1998.

[23] SPENCER, P., WANG, Y., WALKER, M.P., et al., "Interfacial chemistry of the dentin/adhesive bond". Journal of Dental Research, v. 79, n. 7, pp. 1458-1463, 2000.

[24] OLIVEIRA, M. S. A. L. Influência da clorexidina e do monômero 10-MDP na adesão ao esmalte e à dentina, Dissertação de M.Sc., Instituto Superior de Ciências da Saúde Egas Moniz, Caparica, Portugal, 2015.

\section{ORCID}

Eric Costa Carvalho Jayme Pereira de Gouvêa

Ágatha Borges Teixeira

Cláudio Luís de Melo-Silva

Tereza Cristina Favieri de Melo-Silva https://orcid.org/0000-0001-9169-6303

https://orcid.org/0000-0003-0045-4873

https://orcid.org/0000-0003-0988-0844

https://orcid.org/0000-0001-5093-2189

https://orcid.org/0000-0001-5309-7190 